\title{
Sudden unexpected death in epilepsy
}

\section{Assessing the risk factors}

Milena Pavlova, MD

Neurology ${ }^{\circledR}$ 2020;94:e436-e438. doi:10.1212/WNL.0000000000008928

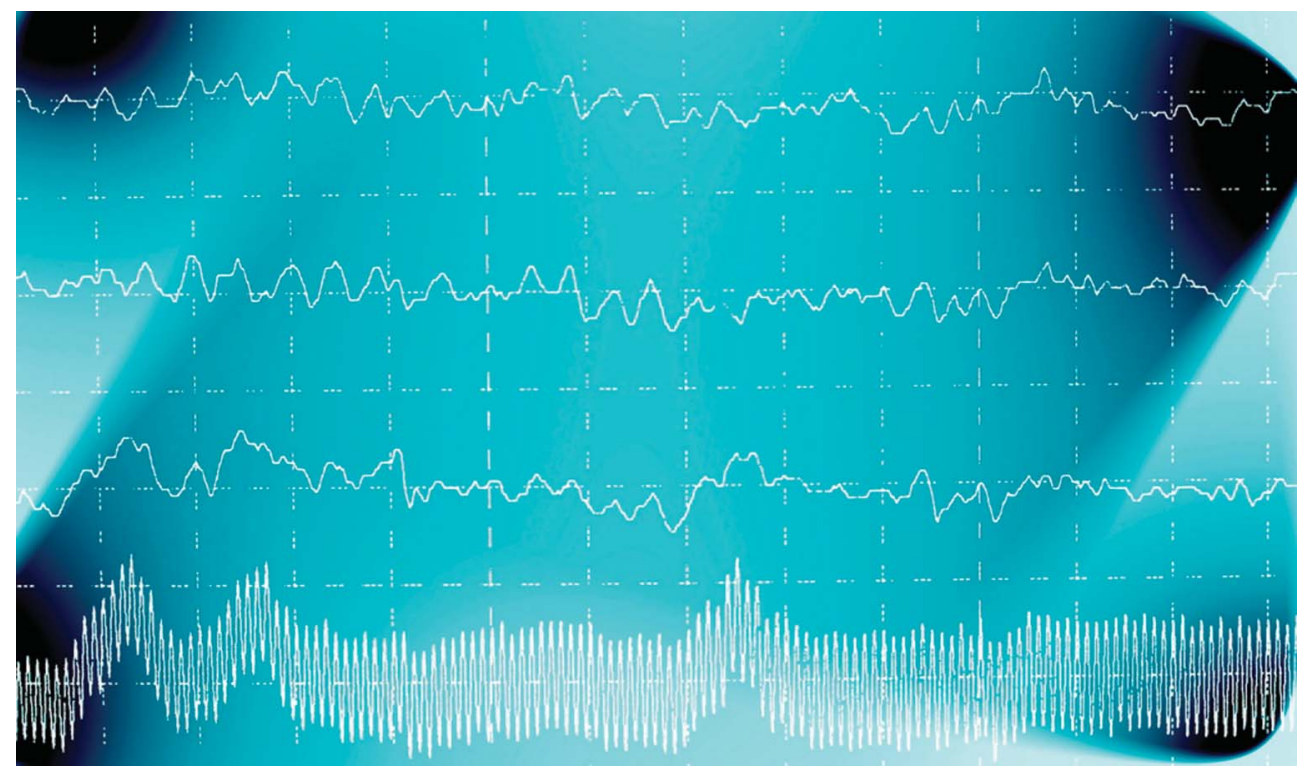

In their study "Clinical risk factors in SUDEP: A nationwide population-based case-control study," Sveinsson et al. ${ }^{1}$ examine the risk factors for sudden unexpected death in epilepsy (SUDEP). They examined the national registry of Sweden, which contains information on all patients seen in a Swedish hospital with the goal of identifying what features are particularly important in predicting risk of sudden death in people with epilepsy.

\section{What questions did the research examine in this study?}

Previous studies on SUDEP have found several main risk factors. These include poor control of seizures with antiseizure medications, frequent seizures, and convulsive seizures. Often the death occurs at night. Several recent studies report more breathing abnormalities with seizures that occur from sleep. Many of the individuals who die of SUDEP are found face down, so a possible effect of suffocation has been considered.

Research on SUDEP is difficult - unlike studies that can examine effect by a trial, studies on death, including SUDEP, can only use proxy measures such as abnormalities of heart and breathing. The alternative is to examine patients' history and medical records. Historical—or retrospective-research is complicated by much loss of data. For example, information may be lost when patients are seen in multiple different hospitals or move to multiple different places. This results in limited information. This makes the current study especially helpful because the national health system in Sweden allows a reliable review of health history preceding the death of a patient in a comprehensive and reliable way.

The researchers of this study examined a large national database in Sweden comparing individuals who had died of SUDEP and individuals who were alive and had epilepsy. 


\section{What are the main findings of the study?}

The authors identified 255 SUDEP cases and compared risk factors to those of 1,148 patients with epilepsy who were of the same sex and still alive. The most striking finding was that the risk of SUDEP was increased 15 times in those who had convulsions at night within the previous year. Furthermore, those who lived alone had a 5 times greater risk of dying.

Other risks included using recreational drugs and alcohol. These findings confirm prior reports of the dangers of frequent convulsions, particularly those that occur at night. The authors found that more than two-thirds of the deaths of those who live alone could potentially be prevented if the patient had someone to help.

\section{What does this mean for patients with epilepsy and their loved ones?}

Currently we do not have any way to prevent SUDEP but taking certain steps may lower risk. Avoidance of recreational drugs and alcohol is one important measure that may be at least partially helpful. Patients should be careful to take their antiepileptic medications as prescribed without missing any doses.

The study highlights the often-underestimated risk from seizures that occur in sleep. It explains why these seizures may be dangerous, even though the patient appears to be protected while in bed. More importantly, it emphasizes the role of a caregiver.

Since being alone at the time of seizure was a strong risk factor for death, it can be inferred that basic care from someone who is near a patient having a convulsion can be life-saving. Simple first aid measures can include removing sharp or hazardous objects around the individual and, if possible, turning the patient on his or her side to avoid breathing in saliva (aspiration). Calling an ambulance may be appropriate if the event is unexpected, if the convulsions are multiple, if there are injuries, or if the patient is having trouble breathing or is otherwise ill. Seizure bracelets with information about medications and any allergies are often helpful. Other studies have examined wearable technology including alerting devices. 


\section{About SUDEP}

Milena Pavlova, MD

Neurology ${ }^{\circledR}$ 2020;94:e436-e438. doi:10.1212/WNL.0000000000008928

\section{What is SUDEP?}

Any one of us can die suddenly and without warning. The good news is that in most of us the probability that this would happen is very low, estimated as about 1 in 40,000. In patients with epilepsy, however, this risk is much higher: 1 in 1,000 overall (or 40 times higher). The risk is particularly high in individuals who continue to have seizures despite medication treatment and in those who have convulsions.

\section{Who is at risk?}

According to the WHO, currently there are 50 million people worldwide who have epilepsy who could be vulnerable to SUDEP. One-third of patients continue to have seizures despite medications.

\section{Are there steps I can take to avoid SUDEP?}

At this time, we do not have any way to entirely prevent SUDEP. However, there are recommendations to lower the risk of SUDEP.

Patients should do the following:

- See a doctor who specializes in epilepsy

- Avoid recreational drugs and alcohol

- Get a good night's sleep

- Take antiepileptic medications as prescribed without missing any doses

- Wear seizure bracelets with information about medications and any allergies

- Solicit basic care from someone who can help with nightly supervision

Caregivers can do the following:

- Learn seizure first aid

- Remove sharp or hazardous objects around the individual

- Turn the patient to the side at night or during sleep to avoid aspiration

- Call an ambulance if the event is unexpected, if there is injury, if the convulsions are multiple, or if the patient has compromised breathing or is otherwise ill.

\section{For more information}

\section{Brain \& Life}

brainandlife.org

Citizens United for Research in Epilepsy (CURE)

cureepilepsy.org

\section{Epilepsy Foundation}

efa.org

\section{Epilepsy Therapy Project}

epilepsy.com

\section{Reference}

1. Sveinsson O, Andersson T, Mattsson P, Carlsson S, Tomson T. Clinical risk factors in SUDEP: a nationwide population-based casecontrol study. Neurology 2020;94:e419-e429. 


\section{Neurology}

\section{Sudden unexpected death in epilepsy: Assessing the risk factors \\ Milena Pavlova}

Neurology 2020;94;e436-e438

DOI 10.1212/WNL.0000000000008928

This information is current as of January 27, 2020

\section{Updated Information \& Services}

\section{References}

Subspecialty Collections

Permissions \& Licensing

Reprints including high resolution figures, can be found at: http://n.neurology.org/content/94/4/e436.full

This article cites 1 articles, 1 of which you can access for free at: http://n.neurology.org/content/94/4/e436.full\#ref-list-1

This article, along with others on similar topics, appears in the following collection(s): All Epilepsy/Seizures http://n.neurology.org/cgi/collection/all_epilepsy_seizures

Information about reproducing this article in parts (figures,tables) or in its entirety can be found online at:

http://www.neurology.org/about/about_the_journal\#permissions

Information about ordering reprints can be found online: http://n.neurology.org/subscribers/advertise

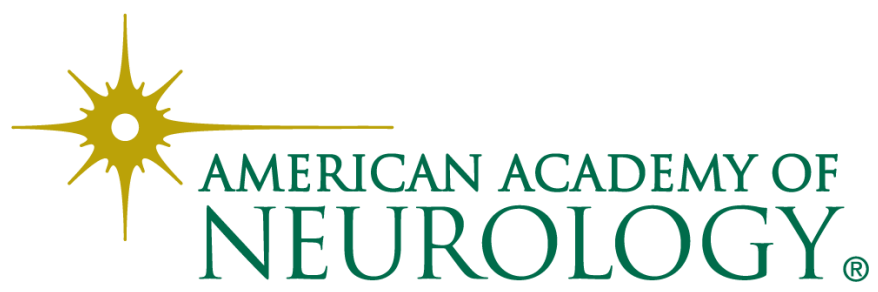

